\title{
Magnetic resonance imaging for accelerated assessment of drug effect and prediction of subsequent radiographic progression in rheumatoid arthritis: a study of patients receiving combined anakinra and methotrexate treatment
}

\author{
M Østergaard, A Duer, H Nielsen, J S Johansen, E Narvestad, B J Ejbjerg, B Baslund \\ J M Moller, H S Thomsen, J Petersen
}

Objectives: By MRI to assess the efficacy of addition of anakinra for controlling synovitis and stopping erosive progression in patients with clinically active RA despite receiving methotrexate, and to determine the predictive value of MRI for subsequent radiographic erosive progression.

Methods: $100 \mathrm{mg}$ anakinra subcutaneously/day was added to the treatment of 17 patients with clinically active RA despite methotrexate. MRI of the non-dominant wrist and 2nd-5th MCP joints (OMERACT evaluation) was performed at weeks 0,12 , and 36 , and radiography of both hands and wrists (modified Sharp evaluation) at weeks 0 and 36.

Results: MRI synovitis scores were not significantly changed. Radiography of both hands and wrists after 36 weeks showed erosive progression in 11 patients, and MRI after 12 weeks in 10 patients. Nine of 10 patients with MRI progression at 12 weeks had radiographic progression at 36 weeks. Baseline MRI synovitis and erosion scores, but no clinical/biochemical parameters, correlated significantly with subsequent erosive progression.

Conclusion: Addition of anakinra did not significantly reduce MRI signs of synovitis, and most patients had progressive joint destruction. Baseline MRI findings predicted subsequent radiographic erosive progression. Unilateral wrist and MCP joint MRI after 12 weeks had a similar sensitivity for detection of erosive progression as bilateral hand and wrist radiography after 36 weeks.

A nakinra (Kineret; Amgen Inc, Thousand Oaks, USA), a recombinant human interleukin 1 receptor antagonist, has been shown to reduce joint inflammation and destruction in patients with rheumatoid arthritis (RA), as assessed by conventional outcome measures-that is, clinical, biochemical, and radiographical examinations. ${ }^{1-3}$

Magnetic resonance imaging (MRI) is more sensitive for the detection of both inflammatory (synovitis) and destructive (erosive) joint changes than clinical examination and radiography. ${ }^{4-6}$ Thus, MRI offers improved opportunities for investigating the course of joint inflammation and destruction during new therapeutic approaches, as in this case interleukin 1 blockade.

The aim of the present study was, by means of MRI, to describe the course of inflammation and destruction of RA joints during combined anakinra and methotrexate (MTX) treatment in patients with RA with high clinical activity despite MTX, and to compare the MRI findings with findings obtained by conventional clinical, biochemical, and radiographic methods. Furthermore, the ability of pretreatment MRI to predict subsequent erosive progression on radiographs was investigated.

\section{PATIENTS AND METHODS}

Seventeen patients with RA (fulfilling American College of Rheumatology 1987 criteria for $\mathrm{RA}^{7}$ ) at the departments of rheumatology of the Copenhagen university hospitals at Herlev and Rigshospitalet, Denmark, enrolled in an open label, single arm, 36 week follow up study (Amgen protocol number 20000258 ), were included in this supplementary investigator initiated amendment, involving repeated MRI and $x$ ray examinations.

All patients ( 13 women, four men; median age 55 years (range 33-73), disease duration 13 years (range 2-37), number of previous disease modifying antirheumatic drugs 3 (range $1-7)$ ), received $100 \mathrm{mg}$ anakinra subcutaneously daily and concomitant MTX (median $15 \mathrm{mg}$ /week (range 520 ), initiated $\geqslant 3$ months before baseline). These doses were kept stable during the trial, as were doses of oral prednisolone (median $0 \mathrm{mg} /$ day (range 0-10)) and non-steroidal antiinflammatory drugs. No intramuscular or intra-articular steroid was given.

All patients signed a separate informed consent for inclusion in this study amendment. The study and the amendment were approved by the local independent ethics committee, and conducted according to the principles of the Declaration of Helsinki. Amgen Inc had no influence on, or involvement in, the planning of this investigator initiated study, the data analysis, or the preparation of the manuscript.

Standard clinical assessments were performed at baseline and after 2, 4, 12, 24, and 36 weeks (table 1).

Conventional radiographs ( $x$ ray), including posteroanterior (PA) projections of hands and wrists, lateral projection of wrists, and oblique projection of hands, ${ }^{8}$ were obtained on single emulsion films at baseline and after 36 weeks and assessed according to the modified Sharp method. ${ }^{9}$ Furthermore, the number of wrist and metacarpophalangeal (MCP) joints with erosions was counted.

Abbreviations: DAS28, 28 joint count Disease Activity Score; MCP, metacarpophalangeal; MRI, magnetic resonance imaging; MTX, methotrexate; OMERACT, Outcome Measures in Rheumatology Clinical Trials; PA, posteroanterior; PIP, proximal interphalangeal; RA, rheumatoid arthritis; SRM, standardised response mean 
Table 1 Clinical and imaging parameters before and during anakinra and methotrexate combination therapy

\begin{tabular}{|c|c|c|c|c|c|c|}
\hline \multirow[b]{2}{*}{ Variables } & \multirow[b]{2}{*}{ Baseline } & \multirow[b]{2}{*}{ Week 12} & \multirow[b]{2}{*}{ Week 36} & \multicolumn{3}{|c|}{$\begin{array}{l}\text { Change from baseline to week } 36 \\
\text { (No of patients) }\end{array}$} \\
\hline & & & & Increase & No change & Decrease \\
\hline \multicolumn{7}{|l|}{ Clinical/biochemical parameters } \\
\hline Erythrocyte sedimentation rate $(\mathrm{mm} / 1 \mathrm{st} h)$ & $28(14-54)$ & $\begin{array}{l}20(5-46) \\
p<0.01\end{array}$ & $\begin{array}{l}17(4-84) \\
p=0.06(N S)\end{array}$ & 3 & 2 & 12 \\
\hline Swollen joint count (0-28) & $7(0-22)$ & $\begin{array}{l}5(0-10) \\
p<0.05\end{array}$ & $\begin{array}{l}3(0-8) \\
p<0.01\end{array}$ & 4 & 0 & 13 \\
\hline Tender joint count (0-28) & $10(3-24)$ & $\begin{array}{l}3(0-15) \\
p<0.01\end{array}$ & $\begin{array}{l}2(0-12) \\
p<0.001\end{array}$ & 2 & 0 & 15 \\
\hline Patients global assessment of pain (VAS 0-100) & $69(30-85)$ & $\begin{array}{l}44(4-84) \\
p<0.01\end{array}$ & $\begin{array}{l}44(6-80) \\
p<0.01\end{array}$ & 1 & 0 & 16 \\
\hline $\begin{array}{l}\text { Patients global assessment of disease activity } \\
\text { (VAS 0-100) }\end{array}$ & $70(45-93)$ & $\begin{array}{l}37(3-87) \\
p<0.05\end{array}$ & $\begin{array}{l}41(9-84) \\
p<0.001\end{array}$ & 2 & 0 & 15 \\
\hline Health Assessment Questionnaire (HAQ) (0-3) & $1.75(0.63-2.75)$ & $\begin{array}{l}1.62(0-2.38) \\
p<0.01\end{array}$ & $\begin{array}{l}1.50(0.25-2.50) \\
p<0.05\end{array}$ & 1 & 1 & 15 \\
\hline DAS28 (ESR based) & $5.6(3.9-7.2)$ & $\begin{array}{l}4.3(2.4-6.4) \\
p<0.01\end{array}$ & $\begin{array}{l}3.8(2.6-6.6) \\
p<0.01\end{array}$ & 2 & 0 & 15 \\
\hline \multicolumn{7}{|c|}{ MRI parameters (non-dominant wrist and 2 nd-5th MCP joints) } \\
\hline Synovitis score $(0-21)$ & $11(3-21)$ & $\begin{array}{l}13(2-21) \\
p=0.90 \text { (NS) }\end{array}$ & $\begin{array}{l}14(3-21) \\
p=0.22(N S)\end{array}$ & 4 & 4 & 9 \\
\hline Bone oedema score (0-69) & $5(0-45)$ & $\begin{array}{l}5(0-28) \\
p=0.08(N S)\end{array}$ & $\begin{array}{l}4(0-27) \\
p=0.06(N S)\end{array}$ & 1 & 7 & 9 \\
\hline Erosion score (0-230) & $17(0-116)$ & $\begin{array}{l}19(0-124) \\
p<0.01\end{array}$ & $\begin{array}{l}21(1-122) \\
p<0.01\end{array}$ & 12 & 3 & 2 \\
\hline No of bones with erosion (0-23) & $10(0-18)$ & $\begin{array}{l}10(0-17) \\
p=0.09 \text { (NS) }\end{array}$ & $\begin{array}{l}11(1-18) \\
p<0.05\end{array}$ & 10 & 4 & 3 \\
\hline \multicolumn{7}{|l|}{$x$ Ray parameters (bilateral wrist, MCP and PIP joints) } \\
\hline Modified Sharp score - total $(0-314)$ & $50(1-233)$ & Not done & $\begin{array}{l}59(2-243) \\
p<0.05\end{array}$ & 13 & 0 & 4 \\
\hline Modified Sharp score-erosions (0-170) & $26(0-125)$ & Not done & $\begin{array}{l}29(0-140) \\
p<0.01\end{array}$ & 11 & 4 & 2 \\
\hline $\begin{array}{l}\text { Modified Sharp score-joint space narrowing } \\
(0-144)\end{array}$ & $34(0-108)$ & Not done & $\begin{array}{l}36(2-103) \\
p=0.86 \text { (NS) }\end{array}$ & 9 & 2 & 6 \\
\hline
\end{tabular}

Except when otherwise stated, values are medians (ranges). The $\mathrm{p}$ values denote changes compared with baseline values (Wilcoxon-Pratt test). DAS, Disease Activity Score; ESR, erythrocyte sedimentation rate; VAS, visual analogue scale; NS, not significant.

MRI of the non-dominant wrist and 2nd-5th MCP joint was performed at baseline and after 12 and 36 weeks. A $0.23 \mathrm{~T}$ MR system (Panorama $0.23 \mathrm{~T}$, Philips, Best, The Netherlands), equipped with a receive-only solenoid coil and localised at the Department of Radiology, the Copenhagen University Hospital at Herlev, was used. Coronal and axial $\mathrm{T}_{1}$ weighted three dimensional fast field echo sequences (slice thickness $1.5 \mathrm{~mm}$; matrix $328 \times 420$, field of view $140 \mathrm{~mm}$ (coronal) or $120 \mathrm{~mm}$ (axial)) and a coronal $\mathrm{T}_{2}$ weighted short tau inversion recovery (STIR) sequence (TSHIRT, slice thickness $3.5 \mathrm{~mm}$, field of view $180 \mathrm{~mm}$, matrix $216 \times 256$ ) were performed. The $\mathrm{T}_{1}$ weighted sequences were repeated after intravenous injection of $0.2 \mathrm{ml} / \mathrm{kg}$ of the contrast agent Omniscan (GE Healthcare, Amersham, United Kingdom).

The MR images were scored for synovitis, bone oedema, and bone erosions according to the latest "Outcome Measures in Rheumatology Clinical Trials" (OMERACT) recommendations (fig 1 ). ${ }^{10}$

Radiographs were read by an experienced musculoskeletal radiologist and MRI scans by a rheumatologist trained in evaluation of MR images of RA joints. Readers were unaware of the chronological order of the images and of clinical, biochemical, and other imaging data.

\section{Statistical analysis}

The Wilcoxon-Pratt test was used to analyse changes within the patient. Spearman's test of rank correlation was used for correlation analyses. The standardised response mean (SRM) was calculated for changes in MRI and radiographic scores. Values of $\mathrm{p}<0.05$ were considered significant.

\section{RESULTS}

\section{Clinical and imaging findings}

At baseline, all patients had clinically active RA (median 28 joint count Disease Activity Score (DAS28) score 5.6, range 3.9-7.2) (table 1). Clinical disease activity parameters were significantly reduced at weeks 12 and 36 (Wilcoxon-Pratt, $\mathrm{p}<0.001$ to $\mathrm{p}<0.05$ ) (table 1 ). At week 36, five, six, and six patients showed good, moderate, and no EULAR response. ${ }^{11}$ Five patients fulfilled the EULAR criteria for low disease activity (DAS28 $<3.2$ ), but no patients had clinical remission (DAS28<2.6). ${ }^{12}$

Radiography of both hands and wrists, assessed by the modified Sharp method, showed progression in bone erosions in $11 / 17$ patients during the 36 week treatment period, while the median total Sharp score increased from 50 (range 1-233) at baseline to 59 (range 2-243) at week 36 $(p<0.05)$ (table 1$)$. In particular, the erosion component of the score increased $(\mathrm{p}<0.01)$, while the joint space narrowing component showed no significant change.

Table 1 gives the MRI scores of synovitis, bone oedema, and bone erosions. The MRI synovitis scores and bone oedema scores did not change significantly during the study. The MRI erosion score at baseline ranged from 0 to 116 (median 17). A significant increase was seen at week 12 (median 19, p <0.01) and at week 36 (median 21, p <0.01) (table 1). The MRI erosion score showed progression in 12/17 patients during the 36 week follow up period. The SRM for the $x$ ray modified Sharp score change from week 0 to 36 was 0.60 , while for the OMERACT MRI erosion score it was 0.77 for weeks $0-12$ and 0.79 for weeks $0-36$. At 12 weeks, MRI 

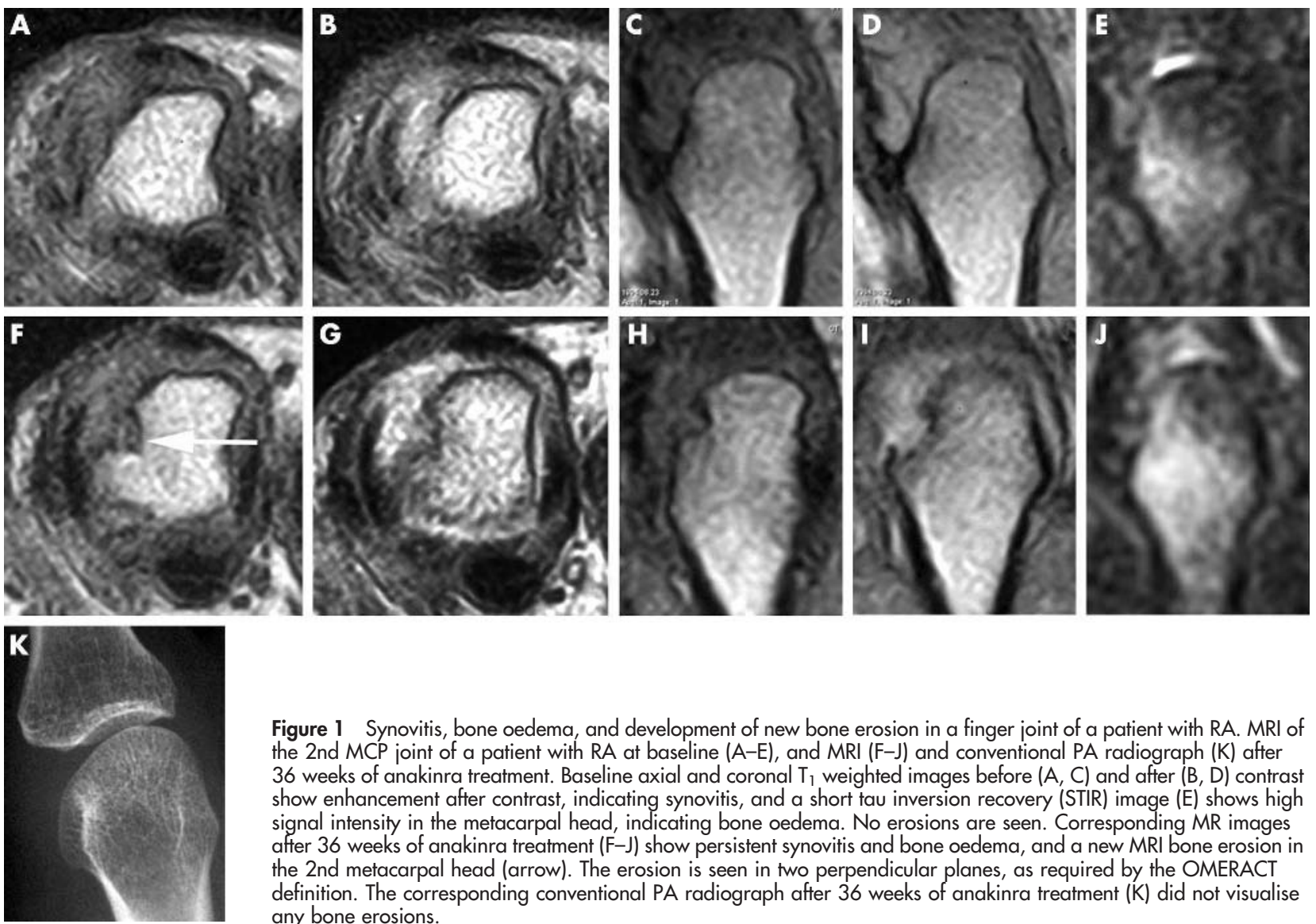

Figure 1 Synovitis, bone oedema, and development of new bone erosion in a finger joint of a patient with RA. MRI of the 2nd MCP joint of a patient with RA at baseline (A-E), and MRI (F-J) and conventional PA radiograph $(K)$ after 36 weeks of anakinra treatment. Baseline axial and coronal $T_{1}$ weighted images before $(A, C)$ and after $(B, D)$ contrast show enhancement after contrast, indicating synovitis, and a short tau inversion recovery (STIR) image (E) shows high signal intensity in the metacarpal head, indicating bone oedema. No erosions are seen. Corresponding MR images after 36 weeks of anakinra treatment ( $\mathrm{F}-J)$ show persistent synovitis and bone oedema, and a new MRI bone erosion in the 2 nd metacarpal head (arrow). The erosion is seen in two perpendicular planes, as required by the OMERACT definition. The corresponding conventional PA radiograph after 36 weeks of anakinra treatment (K) did not visualise any bone erosions.

showed progression in 10 patients. In other words, unilateral MRI of wrist and MCP joints after 12 weeks detected erosion progression in a similar number of patients as bilateral $x$ ray examination of MCP, proximal interphalangeal (PIP), and wrist joints after 36 weeks (11 patients). Nine of the 10 patients with MRI progression at 12 weeks had $x$ ray progression at 36 weeks.

\section{Baseline findings versus erosive progression on radiographs}

As the only baseline parameter, the MRI erosion score was correlated with the change in the radiographic total Sharp score during the 36 weeks of follow up $\left(r_{\mathrm{s}}=0.55, \mathrm{p}<0.05\right)$. Furthermore, the baseline MRI synovitis score was highly correlated with the increase in the total number of radiographic eroded bones in the wrist, MCP, and PIP joints from baseline to week $36\left(r_{\mathrm{s}}=0.70, \mathrm{p}<0.01\right)$ and with the total Sharp score at week $36\left(r_{\mathrm{s}}=0.61, \mathrm{p}<0.05\right)$.

The change in MRI erosion score from baseline to week 12 correlated with the change in total Sharp score from week 0 to week $36\left(r_{\mathrm{s}}=0.55, \mathrm{p}<0.05\right)$.

MRI scores did not correlate with clinical, biochemical, or composite disease activity markers, which, furthermore, did not correlate significantly with radiographic progression.

\section{DISCUSSION}

In this study of patients with severe RA with high clinical disease activity and advanced erosive joint damage, MRI scores of synovitis were not significantly reduced by adding anakinra to methotrexate treatment. Thus, MRI directly showed that anakinra did not efficiently suppress joint inflammation.
The majority of patients with RA showed erosive progression during anakinra treatment, on radiographs as well as on MRI. This is in accordance with the fact that the presence of synovitis is linked to erosive progression, ${ }^{4613}$ and supports the clinical significance of the observed MRI signs of inflammation. As no control group was incorporated, the study design did not allow detection of a potential beneficial effect of anakinra on bone destruction, if present. However, it can with certainty be concluded that erosive progression was not eliminated by combined anakinra and MTX treatment.

Radiography of both hands and wrists, incorporating assessment of both bone erosions and joint space narrowing, found increased damage scores in 13/17 patients at 36 weeks. Eleven patients progressed if only the bone erosion component of the modified Sharp method was considered. In contrast, MRI already at 12 weeks demonstrated erosive progression compared with baseline in 10 patients. Nine of these 10 patients displayed radiographic progression after 36 weeks. The SRM of the 12 week MRI erosion score change was higher than of the 36 week $x$ ray score. These findings illustrate the ability of MRI to visualise erosive progression in patients with RA who are insufficiently treated over a very short time period. This makes MRI very promising for RA clinical trials, because studies as short as 3-4 months may be able to demonstrate significant differences in erosive joint damage.

In our study the baseline MRI findings correlated highly with subsequent radiographic progressive joint destruction. This finding is in accordance with previous findings of a predictive value of MRI findings in early ${ }^{414}$ and established $^{13}{ }^{15}$ RA during conventional disease modifying antirheumatic drug treatment. A predictive value of MRI has, to our knowledge, not previously been demonstrated in patients 
undergoing treatment with anakinra or other biological agents.

This study strongly supports the value of MRI for accelerated assessment of the effect of drugs on structural joint damage and for predicting subsequent radiographic progression.

\section{ACKNOWLEDGEMENT}

We thank radiographer Jan Bovin, and research nurses Helle Hartnack and Gunhild Bukh, for valuable practical assistance; Amgen Scandinavia for financial support of this investigator initiated study; and GE Healthcare, Amersham, United Kingdom, for providing the contrast agent.

Grant supporters: Amgen Scandinavia. The Danish Rheumatism Association.

\section{Authors' affiliations}

M Østergaard, A Duer, H Nielsen, J S Johansen, E Narvestad, B J Ejbjerg, B Baslund, J M Møller, H S Thomsen, J Petersen, Departments and Laboratories of Rheumatology and Departments of Radiology, Copenhagen University Hospitals at Herlev, Hvidovre, and Rigshospitalet, Copenhagen, Denmark

Correspondence to: $\operatorname{Dr} M \varnothing_{\text {stergaard, Department of Rheumatology }}$ Q107, Copenhagen University Hospital at Herlev, Herlev Ringrej 75, DK-2730 Herlev, Denmark; mo@dadlnet.dk

\section{Accepted 15 March 2005}

Published Online First 18 March 2005

\section{REFERENCES}

1 Bresnihan B, Alvaro-Gracia JM, Cobby M, Doherty M, Domlian Z, Emery P, et al. Treatment of rheumatoid arthritis with recombinant human interleukin-1 receptor antagonist. Arthritis Rheum 1998;41:2196-204.

2 Jiang Y, Genant HK, Watt I, Cobby M, Bresnihan B, Aitchison R, et al. A multicenter, double-blind, dose-ranging, randomized, placebo-controlled study of recombinant human interleukin-1 receptor antagonist in patients with rheumatoid arthritis: radiologic progression and correlation of Genant and Larsen scores. Arthritis Rheum 2000;43:1001-9.

3 Cohen S, Hurd E, Cush J, Schiff M, Weinblatt ME, Moreland LW, et al. Treatment of rheumatoid arthritis with anakinra, a recombinant human interleukin-1 receptor antagonist, in combination with methotrexate - results of a twenty-four-week, multicenter, randomized, double-blind, placebocontrolled trial. Arthritis Rheum 2002;46:614-24.

4 McQueen FM, Stewart N, Crabbe J, Robinson E, Yeoman S, Tan PL, et al. Magnetic resonance imaging of the wrist in early rheumatoid arthritis reveals progression of erosions despite clinical improvement. Ann Rheum Dis 1999;58:156-63.

5 Klarlund M, Østergaard M, Jensen KE, Madsen JL, Skjødt H, the TIRA group. Magnetic resonance imaging, radiography, and scintigraphy of the finger joints: one year follow up of patients with early arthritis. Ann Rheum Dis 2000;59:521-8.

6 McGonagle D, Conaghan P, O'Connor P, Gibbon W, Green M, Wakefield RJ, et al. The relationship between synovitis and bone changes in early untreated rheumatoid arthritis. A controlled magnetic resonance imaging study. Arthritis Rheum 1999:42:1706-11.

7 Arnett FC, Edworthy SM, Bloch DA, McShane DJ, Fries JF, Cooper NS, et al. The American Rheumatism Association 1987 revised criteria for the classification of rheumatoid arthritis. Arthritis Rheum 1988;31:315-24.

8 Norgaard F. Earliest roentgenological changes in polyarthritis of the rheumatoid type: rheumatoid arthritis. Radiology 1965;85:325-9.

9 Sharp JT, Young DY, Bluhm GB, Brook A, Brower AC, Corbett M, et al. How many joints in the hands and wrists should be included in a score of radiologic abnormalities used to assess rheumatoid arthritis? Arthritis Rheum 1985;28:1326-35.

10 Østergaard M, Peterfy C, Conaghan P, McQueen F, Bird P, Ejbjerg B, et al. OMERACT rheumatoid arthritis magnetic resonance imaging studies. Core set of MRI acquisitions, joint pathology definitions, and the OMERACT RA-MRI scoring system. J Rheumatol 2003;30:1385-6.

11 van Gestel AM, Prevoo ML, van't Hof MA, van Rijswijk MH, van de Putte LB, van Riel PL. Development and validation of the European League Against Rheumatism response criteria for rheumatoid arthritis. Comparison with the preliminary American College of Rheumatology and the World Health Organization/International League Against Rheumatism Criteria. Arthritis Rheum 1996:39:34-40.

12 Prevoo ML, van Gestel AM, van't Hof MA, van Rijswijk MH, van De Putte LB, van Riel PL. Remission in a prospective study of patients with rheumatoid arthritis. American Rheumatism Association preliminary remission criteria in relation to the disease activity score. $\mathrm{Br} J$ Rheumatol 1996;35:1101-5.

13 Østergaard M, Hansen M, Stoltenberg M, Gideon P, Klarlund M, Jensen KE, et al. Magnetic resonance imaging-determined synovial membrane volume as a marker of disease activity and a predictor of progressive joint destruction in the wrists of patients with rheumatoid arthritis. Arthritis Rheum 1999:42:918-29.

14 McQueen FM, Benton N, Perry D, Crabbe J, Robinson E, Yeoman S, et al. Bone edema scored on magnetic resonance imaging scans of the dominant carpus at presentation predicts radiographic joint damage of the hands and feet six years later in patients with rheumatoid arthritis. Arthritis Rheum 2003;48:1814-27.

15 Østergaard M, Hansen M, Stoltenberg M, Jensen KE, Szkudlarek M, Pedersen-Zbinden $B$, et al. New radiographic bone erosions in the wrists of patients with rheumatoid arthritis are detectable with magnetic resonance imaging a median of two years earlier. Arthritis Rheum 2003;48:21 28-31. 